\title{
Clinical practice guidelines for management of hyperglycaemia in adults with diabetic kidney disease
}

\author{
JANAKA KARALLIEDDE, ${ }^{1}$ PETER WINOCOUR, ${ }^{2}$ TAHSEEN A CHOWDHURY, ${ }^{3}$ PARIJAT DE, ${ }^{4}$ \\ ANDREW H FRANKEL, ${ }^{5}$ ROSA M MONTERO, ${ }^{6}$ ANA POKRAJAC, ${ }^{7}$ DEBASISH BANERJEE, ${ }^{8}$ \\ INDRANIL DASGUPTA, ${ }^{9}$ DAMIAN FOGARTY, ${ }^{10}$ ADNAN SHARIF, ${ }^{11}$ MONA WAHBA, ${ }^{12}$ \\ PATRICK B MARK, ${ }^{13}$ SAGEN ZAC-VARGHESE, ${ }^{14}$ DIPESH C PATEL, ${ }^{15}$ STEPHEN C BAIN ${ }^{16}$
}

\begin{abstract}
A significant percentage of people with diabetes develop chronic kidney disease and diabetes is also a leading cause of end-stage kidney disease (ESKD). The term diabetic kidney disease (DKD) includes both diabetic nephropathy (DN) and diabetes mellitus and chronic kidney disease (DM CKD). DKD is associated with high morbidity and mortality, which are predominantly related to cardiovascular disease.

Hyperglycaemia is a modifiable risk factor for cardiovascular complications and progression of DKD. Recent clinical trials of people with DKD have demonstrated improvement in clinical outcomes with sodium glucose co-transporter-2 (SGLT-2) inhibitors. SGLT-2 inhibitors have significantly reduced progression of DKD and onset of ESKD and these reno-protective effects are independent of glucose lowering. At the time of this update Canagliflozin and
\end{abstract}

Consultant Diabetologist, Guy's and St Thomas' Hospital, London, UK Consultant Diabetologist, East and North Herts Institute of Diabetes and Endocrinology, East and North Herts NHS Trust, Welwyn Garden City, UK Consultant Diabetologist, Royal London Hospital, London, UK

Consultant Diabetologist, City Hospital, Birmingham, UK

Consultant Nephrologist, Imperial College Healthcare NHS Trust, London, UK

6 Consultant Nephrologist, Royal Berkshire NHS Foundation Trust, Reading, UK

Consultant Diabetologist, West Hertfordshire Hospitals, UK

8 Consultant Nephrologist, St George's Hospital, London, UK

Consultant Nephrologist, Heartlands Hospital, Birmingham, UK

10 Consultant Nephrologist, Belfast Health and Social Care Trust, Belfast, UK

11 Consultant Nephrologist, University Hospitals Birmingham, Birmingham, UK

12 Consultant Nephrologist, St Helier Hospital, Carshalton, Surrey, UK

13 Professor of Nephrology, Institute of Cardiovascular and Medical Sciences University of Glasgow, Glasgow, UK

14 Consultant Diabetologist, ENHIDE, East and North Herts NHS Trust, UK

15 Consultant Endocrinologist, Royal Free London NHS Foundation Trust, London; Honorary Associate Professor, University College London, UK

16 Professor of Medicine (Diabetes), Swansea University, Swansea, UK

Address for correspondence: Professor Stephen C Bain Professor of Medicine (Diabetes), Swansea University, Swansea, Wales, SA2 8PP, UK

E-mail: s.c.bain@swansea.ac.uk

https://doi.org/10.15277/bjd.2021.328
Dapagliflozin have been approved for delaying the progression of DKD.

The Association of British Clinical Diabetologists (ABCD) and UK Kidney Association (UKKA) Diabetic Kidney Disease Clinical Speciality Group have un-dertaken a literature review and critical appraisal of the available evidence to inform clinical practice guidelines for management of hyperglycaemia in adults with DKD. This 2021 guidance is for the variety of clinicians who treat people with DKD, including GPs and specialists in diabetes, cardiology and nephrology. Br J Diabetes 2021;21:ONLINE AHEAD OF PUBLICATION

Key words: diabetic kidney disease, management of hyperglycaemia, clinical guideline

This article is an abridged version of the updated clinical guideline and summarises the key recommendations for practice. For definitions of the evidence grades, see Appendix A. The full guidelines are endorsed by Diabetes UK and the Royal College of Physicians of London and are available online at https://abcd.care/position-papers.

This guideline is based on the opinion of the $A B C D$ and UKKA working group and is an update of previous guidance from 2019; a formal systematic review of the literature was not undertaken. There was no lay input in the development of the guidance, however, the final version was endorsed by Diabetes UK. These recommendations are based on a literature review of the Cochrane Library, PubMed/MEDLINE, Google Scholar and Embase carried out initially between October 2013 and December 2016 and further review carried out in June 2020 for the current update, using the following keywords: type 1 diabetes, insulin, chronic kidney disease, nephropathy, hyperglycaemia, hypoglycaemia, insulin, sulfonylureas, metformin, SGLT- 2 inhibitors, pioglitazone, DPP4 inhibitors, GLP-1 analogues and meglitinides.

Glycaemic targets for the prevention and management of diabetic kidney disease

The management of diabetes is predicated on the basis of reducing hyperglycaemia to improve osmotic symptoms, with supportive evidence that this will prevent the onset, and slow down progression, 
Table 1 Proposed glycaemic targets in people with diabetic kidney disease (DKD)

\begin{tabular}{|c|c|c|c|}
\hline Condition & Glycaemic target range & CKD stage and albuminuria & Age \\
\hline \multirow[t]{3}{*}{ Type 1 diabetes } & $48-58 \mathrm{mmol} / \mathrm{mol}(6.5-7.5 \%)^{*}$ & CKD stage 2 with variable microalbuminuria & Younger adults (>18) within 10 years' duration of diabetes \\
\hline & $58-62 \mathrm{mmol} / \mathrm{mol}(7.5-7.8 \%)$ & CKD stages 3-4 and/or albuminuria & The majority of people \\
\hline & 58-68 mmol/mol (7.5-8.5\%) & CKD stage 5 - dialysis & Any age \\
\hline \multirow[t]{3}{*}{ Type 2 diabetes } & $\begin{array}{l}48-58 \mathrm{mmol} / \mathrm{mol}(6.5-7.5 \%)^{*} \\
\text { Aim for }<52 \mathrm{mmol} / \mathrm{mol}(6.9 \%)\end{array}$ & CKD stages 1-2 & $\begin{array}{l}\text { People who are aged }<40 \\
\text { Diet controlled at any age } \neq\end{array}$ \\
\hline & $52-58 \mathrm{mmol} / \mathrm{mol}(6.9-7.5 \%)$ & $\begin{array}{l}\text { CKD stages 3-4 } \\
\text { May be appropriate with a GLP-1 and/or SGLT-2 } \\
\text { inhibitor-based treatment regime without insulin }\end{array}$ & Any age \\
\hline & $58-68 \mathrm{mmol} / \mathrm{mol}(7.5-8.5 \%)$ & $\begin{array}{l}\text { CKD stages 3-4 and those with CKD stage } 5 \text { who } \\
\text { are on dialysis. Especially in people with albuminuria } \\
\text { who are on an insulin-based regimet }\end{array}$ & Any age \\
\hline \multicolumn{4}{|c|}{$\begin{array}{l}\text { *Confirmatory blood glucose or flash glucose monitoring if concern of hypoglycaemia and/or anaemia. } \\
\text { †Recognition of cardio-renal benefits with SGLT-2 inhibitors (and potentially GLP-1 analogue therapy) independent of glycaemic effect. } \\
\text { ‡Over } 20 \% \text { of people with DKD (especially older people aged }>75 \text { ) solely dietary controlled can have HbA } 1 \mathrm{c} 42-48 \mathrm{mmol} / \mathrm{mol}(6-6.5 \%) \text { without hypoglycaemia. } \\
\text { These recommendations are based on the opinion of the Writing Group as there is limited high-grade evidence in DKD. } \\
\text { CKD, chronic kidney disease; GLP-1, glucagon-like peptide 1; SGLT-2, sodium glucose co-transporter-2. }\end{array}$} \\
\hline
\end{tabular}

of renal and vascular complications over time. The precise level of glycaemic control that delivers optimal benefit remains contentious because, inevitably, the individualised approach to care and the evidence base from different cohorts do not allow clear extrapolation. People with DKD require multifaceted and comprehensive care and other aspects such as blood pressure and lipid management, are reviewed separately (please see https://abcd.care/posit ion- papers).

The glycaemic management of type 1 diabetes and type 2 diabetes and the respective renal benefits require separate consideration, which in part reflects the different evidence base and lifetime risks of complications with the greater risk for hypoglycaemia that arises when several concurrent therapies are used alongside insulin as renal function deteriorates. In addition, the risk-benefit equation of tighter glycaemic control for renal and vascular complications alters as DKD progresses.

Individualised $\mathrm{HbA}_{1 \mathrm{c}}$ targets should be applied in the management of people with DKD, using the levels suggested in Table 1. People with DKD are likely to have multiple factors (e.g. anaemia, uraemia, acidosis, reduced circulating albumin levels) which can influence interpretation of $\mathrm{HbA}_{1 c}$ or alternative glycaemic indices such as fructosamine or glycated albumin. In this setting using capillary glucose measures or continuous blood or flash glucose monitoring may be required. In addition, given the potential for the deterioration of renal function over time, regular monitoring of eGFR is necessary, as this could impact on the type and dosage of diabetes therapies, as well as the appropriate glycaemic target. Furthermore the presence of DKD significantly increases the risk of hypoglycaemia, an effect which is most pronounced as eGFR declines. Consideration of the risks of hypoglycaemia and related patient education on prevention and self-management is required when managing glycaemic control in DKD. ${ }^{1}$

There has been an important shift in emphasis in recent guidance from the American Diabetes Association, the European Association for the Study of Diabetes, and the European Society for Cardiology. There is now specific emphasis on selection of SGLT-2 inhibitors or GLP-1 receptor agonists where, in addition to glucose lower-ing, these therapies should be considered in people with DKD where there is an evidence base for cardio-renal protection. ${ }^{1,2}$

\section{Impact of intensification of glycaemic control on DKD in people with type 1 diabetes}

The Diabetes Control and Complications Trial/Epidemiology of Diabetes Interventions and Complications (DCCT/EDIC) studied adolescents and adults with type 1 diabetes who were intensively managed for a mean duration of 6.5 years to a target $\mathrm{HbA}_{1 \mathrm{c}}$ of $42 \mathrm{mmol} / \mathrm{mol}$ (6\%) (achieved $55 \mathrm{mmol} / \mathrm{mol}(7.2 \%)$ ). The study demonstrated reduced incidence of development of microalbuminu-ria in the intensive control arm. $^{3}$ Furthermore, ongoing surveillance for up to 18 years with less intensive glycaemic control $\left(\mathrm{HbA}_{1 \mathrm{c}}\right.$ subsequently maintained at a mean of $64 \mathrm{mmol} / \mathrm{mol}$ (8\%) showed that people in the original intensive group continued to experience lower rates of incident microalbuminuria and macroalbuminuria. They also had less progression to CKD stage 3 (eGFR $<60 \mathrm{~mL} / \mathrm{min} / 1.73 \mathrm{~m}^{2}$ ) and hypertension than the original control group. ${ }^{3}$ A country-wide, registry-based observational study from Sweden confirmed increased $\mathrm{HbA}_{1 \mathrm{c}}$ values remain a powerful risk factor for death after adjustment for renal complications, which indicates a residual risk associated with poor glycaemic control. ${ }^{4}$ However, all-cause and cardiovascular mortality, in those with renal disease was virtually unchanged for people with a timeupdated $\mathrm{HbA}_{1 \mathrm{c}}$ of $53-62 \mathrm{mmol} / \mathrm{mol}(7.0 \%-7.8 \%)$ versus those with values of $52 \mathrm{mmol} / \mathrm{mol}(6.9 \%)$ or lower, which suggests that there is no additional benefit of tighter glycaemic control in those with type 1 diabetes who have renal disease. ${ }^{4}$

Thus it would be appropriate to reduce the develop-ment and progression of nephropathy via tight glycaemic control in younger people $\mathrm{HbA}_{1 \mathrm{c}}$ target individualised to $48-58 \mathrm{mmol} / \mathrm{mol}(6.5 \%-$ $7.5 \%)$, with a requirement to at least maintain moderate control $\mathrm{HbA}_{1 \mathrm{c}}$ of $<63 \mathrm{mmol} / \mathrm{mol}(7.9 \%)$ after a period of 10 years. ${ }^{3} \mathrm{How}$ ever the burden and risks of hypoglycaemia with tighter glycaemic 
control has to be considered with this approach and an individualised target should apply.

It may still be reasonable to aim for a $\mathrm{HbA}_{1 \mathrm{c}}$ of $58-62$ $\mathrm{mmol} / \mathrm{mol}(7.5-7.8 \%)$ in people with type 1 diabetes who have CKD stages 3-4, unless values of $48-58 \mathrm{mmol} / \mathrm{mol}(6.5 \%-7.5 \%)$ are achievable without significant hypoglycaemia risk in those who are younger (below the age of 40 years) (please see levels suggested in Table 1). Access to continuous blood or flash glucose monitoring will hopefully enable $\mathrm{HbA}_{1 \mathrm{c}}$ targets to be met while reducing the frequency of hypoglycaemia.

Impact of intensification of glycaemic control on DKD in people with type 2 diabetes

With the exception of younger people who have type 2 diabetes (below the age of 40) where the lifetime renal-cardiovascular disease risk may justify similar glycaemic targets to those with type 1 diabetes, the evidence base for intensive glycaemic control comes from several sources with broadly different trial design and outcomes.

Two meta-analyses demonstrated that, although intensive glucose control target $\mathrm{HbA}_{1 \mathrm{c}} 43-54 \mathrm{mmol} / \mathrm{mol}(6.1 \%-7.1 \%)$ can lead to a reduced incidence of microalbuminuria and macroalbuminuria in people with type 2 diabetes, however there was no significant impact on clinical renal outcomes such as a doubling of serum creatinine, progression to ESKD or death from kidney disease. ${ }^{5,6} \mathrm{~A}$ more recent meta-analysis implied that intensive glycaemic control had benefits in reducing some renal outcomes but the heterogeneity of glycaemic targets limits the validity of that conclusion. ${ }^{7}$

\section{$\mathrm{HbA}_{1 \mathrm{c}}$ targets for people who have type 2 diabetes and DKD}

Individualised $\mathrm{HbA}_{1 \mathrm{c}}$ targets should be applied in the management of people with DKD, using the levels suggested in Table 1. These target ranges are based on opin-ion of the writing committee as there is limited high grade evidence in people with DKD.

At present, it would be prudent to consider a $\mathrm{HbA}_{1 \mathrm{c}}$ target of $58 \mathrm{mmol} / \mathrm{mol}(7.5 \%)$ for most people with DKD if their glucose lowering therapies include insulin and a target of up to $68 \mathrm{mmol} / \mathrm{mol}(8.4 \%)$ in older people with more advanced CKD (stage 4 and above). The risks of hypoglycaemia are greater in people with diabetes and CKD especially if people are on insulin treatment or sulphonylurea or glinides. Individualised pragmatic glycaemic goals that balance the benefits and risks of intensive glucose lowering in people with type 2 diabetes DKD and patient education on hypoglycaemia avoidance and self-management are needed.

It remains to be seen whether it is appropriate and safe to have a lower glycaemic $\mathrm{HbA}_{1 c}$ target of $52 \mathrm{mmol} / \mathrm{mol}(6.9 \%)$ as more GLP-1 and SGLT-2 inhibitor-focused treatments are being used when the eGFR is $>30 \mathrm{~mL} / \mathrm{min} / 1.73 \mathrm{~m}^{2}$, both for people with and without cardiovas-cular disease.

From the current evidence, there is no basis to seek $\mathrm{HbA}_{1 c}$ values of lower than $52 \mathrm{mmol} / \mathrm{mol}$ (6.9\%) in older people with type 2 diabetes and DKD through medication.

\section{Renal function measurements in determining}

\section{medication dosages in diabetes}

We recommend that eGFR is utilised, preferably using the more accurate Chronic Kidney Disease Epidemiology Collaboration (CKD- EPI) equation when determining whether certain therapies can be used or to adjust medication dosages in diabetes. ${ }^{8}$ It is important to recognise that eGFR equations have several limitations. ${ }^{9}$ There is also an ongoing important discussion on the continued use of ethnicity in eGFR equations and its potential impact on prescribing practice and clinical care. ${ }^{10}$

\section{Glucose-lowering therapies for people who have type 2 diabetes and DKD}

The selection of individual classes of drug, tailored to the additional comorbidities that are frequently seen along-side DKD, will also influence therapy selection (Table 2). In addition, certain combinations of different classes of drugs would need judicious consideration. Although these guidelines focus on individual classes of glucose-lowering drug, combinations of different classes will frequently be prescribed to people with DKD. There is a relative dearth of studies that specifically evaluate different drug combinations in people with DKD, and this is clearly an area for both further research and clinical audit.

\section{Recommendations}

1 Individualised $\mathrm{HbA}_{1}$ targets should be applied in the management of people with DKD, using the levels suggested in Table 1. (Grade 1B).

2 Additional comorbidities, that are frequently seen alongside DKD, and risk of hypoglycaemia should also influence therapy selection and $\mathrm{HbA}_{1 \mathrm{c}}$ targets. In people who progress to advanced stages of DKD (eGFR $<45 \mathrm{~mL} / \mathrm{min}$ ) or those with fast progression of DKD more frequent monitoring of $\mathrm{HbA}_{1 \mathrm{c}}$ and renal function may be required. (Tables 1 and 2) (Grade 1B).

3 Certain combinations of different classes of drugs need judicious consideration, but appropriate combinations of different classes will frequently be needed to manage DKD (Grade 2D).

\section{Insulin therapy in people with CKD stages 1-3}

Many oral hypoglycaemic therapies are contraindicated in DKD or may be ineffective in people with long-standing type 2 diabetes, and hence insulin is frequently prescribed. A common clinical scenario is the cessation of metformin or other glucoselowering therapies as renal function declines, which necessitates insulin therapy to maintain glycaemic control.

In the early stages of DKD, insulin resistance predominates and may worsen, leading to a greater requirement for insulin. Insulin doses, therefore, are frequently high in early DKD, when albuminuria predominates. ${ }^{11}$ As GFR declines, however, insulin requirements diminish, with some studies suggesting a 30\% reduction in insulin requirements when the GFR is $<60 \mathrm{~mL} / \mathrm{min} / 1.73 \mathrm{~m}^{2}$, compared with when the GFR is $>90 \mathrm{~mL} / \mathrm{min} / 1.73 \mathrm{~m}^{2}$. $^{12}$

There are limited data on the use of insulin in mild or moderate DKD with no randomised studies specifically in this population. A meta- analysis of 6-month pooled data from three trials examining the use of insulin glargine U300 in people with CKD 
Table 2 Contraindications to the selection of blood glucose-lowering therapies in people with diabetic kidney disease (DKD) with diabetes mellitus complications

\begin{tabular}{|c|c|c|}
\hline Condition & Drug & Note \\
\hline \multirow[t]{2}{*}{ Retinopathy } & Pioglitazone & Absolute contraindication in diabetic maculopathy \\
\hline & Semaglutide & $\begin{array}{l}\text { Relative contraindication in people with marked hyperglycaemia }\left(\mathrm{HbA}_{1 \mathrm{c}}>91 \mathrm{mmol} / \mathrm{mol}(10.5 \%)\right) \text { who have diabetic } \\
\text { retinopathy requiring active ophthalmology follow-up: caution is advised }\end{array}$ \\
\hline \multirow[t]{2}{*}{ Bone health } & Pioglitazone & $\begin{array}{l}\text { Absolute contraindication in people who have had previous osteoporotic fractures; or relative contraindication in those with } \\
\text { post-menopausal osteoporosis with neuropathy }\end{array}$ \\
\hline & SGLT-2 inhibitors & Relative contraindication in people with established osteoporotic fractures \\
\hline Foot health & SGLT-2 inhibitors & Absolute contraindication if a person has active diabetic foot disease with vascular complications or sepsis \\
\hline \multirow[t]{2}{*}{ Cardiac failure } & Pioglitazone & $\begin{array}{l}\text { Absolute contraindication in people with established treated heart failure and where at-risk people have a raised serum brain } \\
\text { natriuretic peptide (BNP) }\end{array}$ \\
\hline & Saxagliptin & Absolute contraindication in people with treated established heart failure \\
\hline Pancreatic health & GLP-1 analogues & $\begin{array}{l}\text { Absolute contraindication of GLP-1 analogues where an individual has previously documented pancreatitis; relative } \\
\text { contraindication in people who are at risk of pancreatitis with raised triglycerides, those on steroid therapy, those using other } \\
\text { drugs that are associated with pancreatitis or those with documented alcoholism }\end{array}$ \\
\hline \multirow[t]{2}{*}{ Bladder health } & SGLT-2 inhibitors & $\begin{array}{l}\text { Relative contraindication of all medications in this class in people who have documented neuropathic bladder and recurrent } \\
\text { urinary infections }\end{array}$ \\
\hline & Pioglitazone & $\begin{array}{l}\text { Bladder cancer - no current absolute contraindication to continuation of pioglitazone and SGLT-2 inhibitors; relative } \\
\text { contraindication/caution to initiation of pioglitazone and SGLT-2 inhibitors in those with bladder cancer or without } \\
\text { investigation of unexplained haematuria }\end{array}$ \\
\hline Biliary tract health & GLP-1 analogues & Relative contraindication if a person has active gall bladder disease \\
\hline
\end{tabular}

(eGFR<60 $\mathrm{mL} / \mathrm{min}$ ) reported a reduced risk of nocturnal or severe hypoglycaemia by $24 \%$ (RR 0.76; $95 \%$ Cl 0.62-0.94), suggesting a modest benefit of insulin glargine U300 over insulin glargine U100 in people with DKD. ${ }^{13}$

A recent study comparing glargine $U 300$ with insulin degludec U100 in insulin naïve T2DM examined glycaemic effects according to renal status as secondary endpoint. There was a suggestion of greater reduction in $\mathrm{HbA}_{1 \mathrm{c}}$ without an increase in hypoglycaemia in people on glargine $U 300$ in people with eGFR $<60 \mathrm{~mL} / \mathrm{min}$, but the relatively small number of people with DKD in the study limits any firm conclusions. ${ }^{14}$

\section{Insulin therapy in people with CKD stages 4-5 (pre-dialysis)}

The use of insulin therapy or the type of insulin therapy has not been subjected to randomised study in people with CKD stages 4- 5. In these people, loss of clearance of insulin and reduction in gluconeogenesis in the kidneys leads to a falling insulin requirement and, as a consequence, higher risk of hypoglycaemia. In addition, uraemia-induced anorexia and weight loss may also occur, leading to significant reductions in insulin dosing.

Occasionally, insulin requirements may fall low enough to obviate the need for insulin and allow conversion to oral therapy or the cessation of pharmacotherapy altogether. Some guidelines suggest a gradual reduction of the total daily insulin dose to $75 \%$ when the GFR is $10-50 \mathrm{~mL} / \mathrm{min} / 1.73 \mathrm{~m}^{2}$, and to $50 \%$ for a GFR of $<10 \mathrm{~mL} / \mathrm{min} / 1.73 \mathrm{~m}^{2}{ }^{15}$

\section{Insulin therapy in people with ESKD}

Insulin therapy in people with diabetes who are on haemodialysis is dealt with in guidelines that have been produced by the Joint British Diabetes Societies and the Renal Association. ${ }^{16}$

\section{Recommendations}

1 There is no firm evidence that insulin therapy reduces the risk of progressive renal disease. Therefore, the aim of insulin therapy should be to improve glycaemic control and improve quality of life, with a low risk of hypoglycaemia (Grade 1C).

2 Insulin requirements are likely to rise in the early stages of DKD due to increased insulin resistance (Grade 1C).

3 As GFR declines, insulin requirements are likely to diminish through reduced renal insulin clearance. Insulin doses should be reduced as GFR falls, especially in chronic kidney disease (CKD) stage $3 b$ and below. In people with CKD stage $3 b$ and below who are on insulin, and whose $\mathrm{HbA}_{1 \mathrm{c}}$ is $58 \mathrm{mmol} / \mathrm{mol}$ $(7.5 \%)$ or below, reduction of insulin dose should be considered (Grade 1C).

4. People who are treated with insulin should undertake regular glucose monitoring (Grade 1C).

5. In people who are less able to comply with the requirements of a basal bolus regime, once daily regimes with longer-acting insulins should be considered (Grade 1D).

6. If people experience hypoglycaemia on neutral protamine Hagedorn (NPH) insulin or premixed insulins, conversion to analogue insulins may be of benefit (Grade 1C).

\section{Sulfonylureas}


There is very little comparative randomised controlled trial evidence of the use of Sulfonylureas (SUs) in DKD. People with type 2 diabetes and DKD who are on SU treatment are at increased risk of hypoglycaemia. We therefore advise regular capillary blood glucose (CBG) monitoring for people with DKD on SU treatment. All SU should be avoided where possible in advanced renal impairment (e.g. eGFR $<30 \mathrm{~mL} / \mathrm{min} / 1.73 \mathrm{~m}^{2}$ ). Please see the full guidance document for detailed information on the use of SUs in DKD (https://abcd.care/posit ion- papers).

\section{Metformin}

Metformin has been used as a first- line oral drug for people with type 2 diabetes for over 60 years. The dose of metformin should be decreased if eGFR is $<45 \mathrm{~mL} / \mathrm{min} / 1.73 \mathrm{~m}^{2}$ and omitted if eGFR is less than $30 \mathrm{~mL} / \mathrm{min} / 1.73 \mathrm{~m}^{2}$. Treatment should be interrupted in people at risk of tissue hypoxia or sudden deterioration in renal function, for example, dehydration, severe infection, shock, sepsis, acute heart failure, respiratory failure or hepatic impairment, or those who have recently had a myocardial infarction. ${ }^{17}$

A recent systematic review suggests that metformin use in moderate DKD (eGFR 30- $60 \mathrm{~mL} / \mathrm{min} / 1.73 \mathrm{~m}^{2}$ ) confers a mortality benefit of $22 \%$ (HR $0.78 ; 95 \% \mathrm{Cl} 0.63-0.96) .{ }^{18}$ Analysis of a community based cohort of 75,413 people showed that metformin was not associated with an increased risk of lactic acidosis in people with eGFR above $30 \mathrm{~mL} / \mathrm{min} / 1.73 \mathrm{~m}^{2}$, but below this level, risk for acidosis was increased by twofold. ${ }^{19}$ In contrast another systematic review confirmed the absence of any evidence for an increased risk of lactic acidosis, even in patients with an eGFR $<30 \mathrm{~mL} / \mathrm{min} /$ $1.73 \mathrm{~m}^{2} .{ }^{20}$

We acknowledge lack of high quality evidence for the continued use of metformin in people with eGFR between 25$30 \mathrm{~mL} / \mathrm{min}$. Often an individualised and prag-matic approach may be required in people with DKD and eGFR $25-30 \mathrm{~mL} / \mathrm{min} / 1.73 \mathrm{~m}^{2}$ where low dose metformin may be more practical and safer than switching to other glycaemia-lowering drugs such as insulin, which might increase the risk of hypoglycaemia. In this scenario discussion with diabetes and renal specialist teams is required with increased vigilance, education on sick day rules and dose reductions down to $1,000-500 \mathrm{mg} /$ day.

IIn summary, for most people, the benefits of metformin greatly outweigh the very small lactic acidosis risk: a 30\%-40\% reduction in cardiovascular and diabetes events versus a risk of lactic acidosis of a maximum 5-10 episodes per 100,000 patient-years. Even if the presence of impaired renal function increases this risk by 10 or even 100-fold, the benefits continue to outweigh the risks. In recognising that there may be subgroups of people who are at higher risk of lactic acidosis (not just due to impaired renal function), however, the practical advice for clinicians and people contained in Table 3 is relevant and in general supports the ongoing use of metformin for peo-ple with stable CKD stage 3.

\section{Recommendations}

1 Metformin can be used down to an eGFR of $30 \mathrm{~mL} / \mathrm{min} / 1.73 \mathrm{~m}^{2}$ and should be stopped if eGFR is persistently less than 30 $\mathrm{mL} / \mathrm{min} / 1.73 \mathrm{~m}^{2}$. The dosage should be reduced when the eGFR falls below $45 \mathrm{~mL} / \mathrm{min} / 1.73 \mathrm{~m}^{2}$ (Grade 1B).

2. Metformin should be withheld during periods of acute illness, particularly when a person has acute kidney injury (AKI). Everyone who is treated with metformin should be given sick day guidance, which should be reiterated at every medication review (Grade 1B).

3. Metformin should be withheld prior to and shortly after any procedure that requires the use of radiographic contrast media (Grade 1B).

\section{Dipeptidyl peptidase-4 inhibitors}

Dipeptidyl peptidase-4 inhibitors (DPP-4 inhibitors) bind selectively to DPP-4 and prevent the rapid hydrolysis of glucagon-like peptide 1 (GLP-1). They have a modest glucose-lowering effect, compared with other oral hypoglycaemic agents. DPP-4 inhibitors are known to have a very low risk of hypoglycaemia and are generally associated with a favourable safety and tolerability profile in people with type 2 diabetes and mild-to-severe renal impairment. ${ }^{21}$

\section{Recommendations}

1 We recommend that people with DKD of all stages are suitable for treatment with DPP-4 inhibitors (Grade 1B).

2. We recommend that doses of DPP-4 inhibitors are appropriately reduced in accordance with the degree of renal impairment (including maintenance haemodialysis) except linagliptin (Grade 1B).

3. People with DKD can be safely prescribed DPP-4 inhibitors without the risk of hypoglycaemia or weight gain at all stages of renal disease (Grade 1B).

4. There are no current data to suggest that DPP-4 inhibitors (except saxagliptin) are associated with an excess risk of hospitalisation for heart failure (Grade 1A).

\section{Pioglitazone}

Pioglitazone is one of the few oral glucose- lowering drugs that is licensed for use in people with eGFR of $<30 \mathrm{~mL} / \mathrm{min} / 1.73 \mathrm{~m}^{2}$. Pioglitazone should be avoided if there is evi-dence of heart failure or macular oedema. People should be carefully and regularly monitored for fluid retention. Please see the full guidance for detailed information on the use of pioglitazone in DKD (https://abcd.care/position-papers).

\section{Sodium glucose co-transporter-2 inhibitors}

Systematic reviews and meta-analyses suggest a clear beneficial class effect of SGLT- 2 inhibitors on the risk of cardiovascular disease (CVD) and hospitalisation for heart failure. ${ }^{22,23}$ These benefits are consistently observed in people with DKD even at early stages of disease. In view of high risk of CVD in DKD multifactorial interventions that can reduce the burden of CVD are needed and SGLT-2 inhibitor class offers unique advantages in the context of CVD and renal protection. Recent meta-analyses have demonstrated the beneficial effects of SGLT-2 inhibitors on CVD and renal end-points (such as dialysis, transplantation and death due to kidney disease) and these effects are seen irrespec- 
tive of baseline albuminuria, eGFR, $\mathrm{HbA}_{1 c}$ and are inde-pendent of blood glucose-lowering effect or use of renin angiotensin system (RAS) blockade. ${ }^{22-24}$ The first evidence that SGLT-2 inhibitors may have reno-protective properties was a secondary analysis of renal endpoints in the Empagliflozin Cardiovascular Outcome Event Trial in Type 2 Diabetes Mellitus Patients-Removing Excess Glucose (EMPA- REG) OUTCOME trial. ${ }^{25}$ Subsequent cardiovascular outcome trials (CVOT) with other SGLT- 2 inhibitors demonstrated similar reno-protective outcomes which were evaluated as secondary or exploratory outcomes. ${ }^{23}$ Within the SGLT-2 inhibitor class, a recent CVOT with Ertugliflozin did not however demonstrate a statistically significant reduction in cardio-renal endpoints. ${ }^{26}$

This section focusses in detail on recent outcome trials where renal outcomes were assessed as primary endpoint in DKD and to date only two trials have been published.

Canagliflozin and Renal Events in Diabetes with Established Nephropathy Clinical Evaluation (CREDENCE) was the first study of an SGLT- 2 inhibitor to have renal outcomes in its primary composite endpoint. ${ }^{27}$ People with type 2 diabetes and albuminuric chronic kidney disease were randomised to receive canagliflozin $100 \mathrm{mg}$ once daily or placebo. All participants had an eGFR of 30 to $<90$ $\mathrm{mL} / \mathrm{min} / 1.73 \mathrm{~m}^{2}$, albuminuria [urine albumin:creatinine ratio (ACR) $>33.9-565 \mathrm{mg} / \mathrm{mmol}(>300$ to $5,000 \mathrm{mg} / \mathrm{g})$ ] and received RAS blockade. Sixty per cent of recruits had an eGFR of 30$60 \mathrm{~mL} / \mathrm{min} / 1.73 \mathrm{~m}^{2}$. The primary endpoint was a composite of ESKD (dialysis, transplantation, or sustained eGFR of $<15 \mathrm{~mL}$ $\mathrm{min} / 1.73 \mathrm{~m}^{2}$ ), a doubling of the serum creatinine or death from renal or cardiovascular causes.

The trial was halted early after a planned interim analysis, at which point 4,401 people had been ran-domised with median follow-up of 2.6 years. The relative risk of the primary endpoint was significantly lower in the canagliflozin group with event rates of 43.2 versus 61.2 per 1,000 patient-years (HR $0.70 ; 95 \% \mathrm{Cl} 0.59$ $0.82 ; p=0.00001)$. The relative risk of the renal-specific composite of ESKD, doubling of the creatinine level, or death from renal causes was lower by 34\% (HR 0.66; 95\% Cl 0.53- 0.81; $\mathrm{p}<0.001$ ) and end-stage kidney disease was lower by $32 \%$ (HR 0.68; $95 \%$ $\mathrm{Cl} 0.54-0.86 ; p=0.002$ ). Participants in the canagliflozin group also had a signifi-cantly lower risk of cardiovascular death, myocardial in-farction, or stroke (HR 0.80; 95\% Cl 0.67- 0.95; $p=0.01$ ) and hospitalisation for heart failure (HR $0.61 ; 95 \% \mathrm{Cl} 0.47-0.80$; $\mathrm{p}<0.001) .{ }^{27}$ Of note, in this high-risk population there was no significant increase in rates of lower limb amputation or fracture, which was only observed with a previous study with canagliflozin but has not reported in CVOTs for dapagliflozin and empagliflozin.

The Dapagliflozin and Prevention of Adverse Outcomes in Chronic Kidney Disease (DAPA-CKD) trial assessed the effect of dapagliflozin on renal and cardiovascular events in people with CKD (both with and without diabetes). ${ }^{28}$ In this study 4,094 participants with an eGFR between $25-75 \mathrm{~mL} / \mathrm{min} / 1.73 \mathrm{~m}^{2}$ and urine ACR of $22.6-565 \mathrm{mg} / \mathrm{mmol}(200-5,000 \mathrm{mg} / \mathrm{g})$ were randomised to receive dapagliflozin $10 \mathrm{mg}$ once daily or placebo. Participants were on stable dose of RAS blockade although those who were unable to take these medications could be included. The mean baseline eGFR was $41.1 \mathrm{~mL} / \mathrm{min} / 1.73 \mathrm{~m}^{2}$ and the median urine $A C R$ was $107.2 \mathrm{mg} / \mathrm{mmol}$ (949 mg/g). The primary outcome was a composite of sustained decline in eGFR of at least 50\%, ESKD, or death from renal or cardiovascular causes. The trial was stopped early because of efficacy. Over a median of 2.4 years, the primary outcome event occurred in 197 of 2,152 participants $(9.2 \%)$ in the dapagliflozin group and 312 of 2,152 participants (14.5\%) in the placebo group (HR $0.61 ; 95 \% \mathrm{Cl} 0.51$ to $0.72 ; \mathrm{p}<0.001$ ) and the number needed to treat to prevent one primary outcome event was (19 [95\% Cl, 15-27]). The hazard ratio for the renal composite of a sustained decline in eGFR of at least $50 \%$, ESKD, or death from renal causes was $0.56(95 \% \mathrm{Cl} 0.45$ to $0.68 ; \mathrm{p}<0.001)$. All-cause mortality was 101 in dapagliflozin participants $(4.7 \%)$ versus 146 subjects (6.8\%) in the placebo group (HR 0.69; $95 \% \mathrm{Cl} 0.53$ to $0.88 ; p=0.004)$. The effects were similar in people with type 2 diabetes to those without. 28

\section{Practical aspects of using SGLT-2 inhibitors}

The observed renal and cardiovascular benefits of SGLT-2 inhibitors are independent of the $\mathrm{HbA}_{1 \mathrm{c}}$ lowering effects of these agents in people with type 2 diabetes and eGFR $>45 \mathrm{~mL} / \mathrm{min} /$. $1.73 \mathrm{~m}^{2}$. In people with diabetes and eGFR $<45 \mathrm{~mL} / \mathrm{min} / 1.73 \mathrm{~m}^{2}$, treatment with SGLT- 2 inhibitors do not lower $\mathrm{HbA}_{1 c}$ significantly. A SGLT-2 inhibitor can be initiated or continued for cardio-renal protection, however, if further glucose lowering is required adding another class of medications to optimise diabetes control is recommended. If Dapagliflozin or Canagliflozin is started for DKD the medication can be continued until ESKD.

Regardless of urine $A C R$, we also recommend the initiation of dapagliflozin as licensed for people with diabetes, heart failure and CKD where eGFR is $>30 \mathrm{~mL} / \mathrm{min} / 1.73 \mathrm{~m}^{2}$. It is likely that all SGLT-2 inhibitors will be effective in these individuals but licence updates are awaited. Please see Tables 3 and 4 for more detailed information on the use of SGLT-2 inhibitors.

Diabetic ketoacidosis (DKA) secondary to SGLT-2 inhibitor is rare in T2DM with reported incidence between 1 in 1000 to 1 in 10,000 people. In the DAPA-CKD trial no increased risk of DKA was observed with dapagliflozin. However in the CREDENCE trial rates of DKA were higher in the canagliflozin group than in the placebo group (2.2 vs. 0.2 per 1000 patient-years). ${ }^{24}$ SGLT-2 inhibitor induced DKA can present with normoglycaemia or moderately raised glucose levels. It is important for clinicians to be aware of this so that diagnosis is not missed.

\section{Recommendations}

1. We recommend the consideration of SGLT- 2 inhibitors in all individuals with type 2 diabetes and DKD with an eGFR $\geq 30 \mathrm{~mL} / \mathrm{min} / 1.73 \mathrm{~m}^{2}$, irrespective of glycaemic control, recognising that this is currently off- licence practice for some drugs in the SGLT-2 inhibitor class. For those with established albuminuria, canagliflozin $100 \mathrm{mg}$ once daily is licenced for renoprotection in DKD and dapagliflozin $10 \mathrm{mg}$ can be initiated down to an eGFR of $15 \mathrm{~mL} / \mathrm{min}$ irrespective of the level of albuminuria (Grade 1A).

2. Where individuals are already receiving treatment with insulin 
Table 3 Action to be taken for selected medications when treating people with diabetic kidney disease (DKD)

\begin{tabular}{|c|c|}
\hline eGFR level & Action to be taken \\
\hline \multicolumn{2}{|l|}{ Metformin } \\
\hline For all & - Practitioners have to weigh up the glycaemic and cardiovascular benefits against the rare risk of associated lactic acidosis. \\
\hline $\begin{array}{l}45-60 \mathrm{~mL} / \mathrm{min} / \\
1.73 \mathrm{~m}^{2}\end{array}$ & $\begin{array}{l}\text { - Continue use in people who were established on metformin, but review the dose in light of glucose control needs. } \\
\text { - For new individuals who have no major active co-morbidities, metformin commencement can be considered if age-related life expectancy is } \\
\text { normal and vascular/diabetes risks are present. } \\
\text { - Increase monitoring of renal function (to every 3-6 months). }\end{array}$ \\
\hline $\begin{array}{l}30-45 \mathrm{~mL} / \mathrm{min} / \\
1.73 \mathrm{~m}^{2}\end{array}$ & $\begin{array}{l}\text { - Continue or commence with caution and explain the risks and benefits to the person. } \\
\text { - Use lowest dose that achieves glycaemic control (suggest a } 50 \% \text { dose up to } 1,000 \mathrm{mg} / \mathrm{day}) \text {. } \\
\text { - Closely monitor renal function (every } 3 \text { months). }\end{array}$ \\
\hline$<30 \mathrm{~mL} / \mathrm{min} / 1.7$ & $\begin{array}{l}\text { - At this level of renal function we cannot give firm recommendations about the ongoing use of metformin. } \\
\text { - Some specialists may choose to use metformin in selected people where they see that the benefits outweigh the risks. } \\
\text { metformin concentrations of }<5 \mathrm{mg} / \mathrm{L} \text {. }\end{array}$ \\
\hline $\begin{array}{l}\text { Recovery from } \\
\text { AKI }\end{array}$ & $\begin{array}{l}\text { - Once urine flow has returned to normal and GFR is }>30 \mathrm{~mL} / \mathrm{min} / 1.73 \mathrm{~m}^{2} \text {, resume metformin at a low dose (eg, 500-1,000 mg/day). } \\
\text { - Monitor glucose control in outpatients and primary care before considering the further need for increasing doses. }\end{array}$ \\
\hline
\end{tabular}

\section{GLP-1 receptor agonists: exenatide (Byetta ${ }^{\mathrm{TM}}$ and Bydureon ${ }^{\mathrm{TM}}$ ), liraglutide, lixisenatide, dulaglutide, semaglutide}

For all - Older people: no dose adjustment is required based on age. Therapeutic experience in people $\geq 75$ years of age is limited

- Paediatric population: the safety and efficacy in children aged up to 18 years have not yet been established. No data are available.

- Should not be used in people with type 1 diabetes mellitus or for the treatment of diabetic ketoacidosis.

- No experience in those with congestive heart failure NYHA class IV and therefore not recommended in these people.

- If pancreatitis is suspected, drug should be discontinued; if confirmed, then should not be restarted. Caution should be exercised in people with a history of pancreatitis.

$>60 \mathrm{~mL} / \mathrm{min} / 1.73 \mathrm{~m}^{2} \bullet$ No renal contraindication to initiation or continuation.

$45-60 \mathrm{~mL} / \mathrm{min} /$ - No renal contraindication to initiation or continuation.

$1.73 \mathrm{~m}^{2}$

$30-45 \mathrm{~mL} / \mathrm{min} / \quad$ - ByettaT ${ }^{\mathrm{TM}}$ and lixisenatide to be used 'with caution' in people with creatinine clearance $30-50 \mathrm{~mL} / \mathrm{min}$, Bydureon ${ }^{\mathrm{TM}}$ should be stopped.

$1.73 \mathrm{~m}^{2} \quad$ Liraglutide, dulaglutide and semaglutide have no renal contraindication to initiation or continuation at standard doses.

$<30 \mathrm{~mL} / \mathrm{min} / 1.73 \mathrm{~m}^{2}$ • Liraglutide, dulaglutide and semaglutide have no renal contraindication to initiation or continuation at standard doses.

Dialysis $\quad$ No current role

AKI (or at risk Review and consider (temporarily) stopping* in people who:

of AKI) - have acute changes in renal function (a fall in eGFR of $>10 \mathrm{~mL} / \mathrm{min} / 1.73 \mathrm{~m}^{2}$ over a period of days or weeks)

- are at risk of AKI such as:

- acute volume depletion and dehydration (eg, gastrointestinal upset, stomas, change in diuretic dose)

- operative procedures with a high risk of hypotension or volume depletion

$\circ$ in the presence of hypotension or shock (eg, severe infection)

- have had previous episodes of AKI.

*Duration of stopping GLP-1 receptor agonist should be based on the likely period of risk.

AKI, acute kidney injury; DPP-4i, dipeptidyl peptidase-4 inhibitors; eGFR, estimated glomerular filtration rate; GLP-1, glucagon-like peptide 1; SGLT-2i, sodium glucose co-transporter-2 inhibitor. 
Table 3 Action to be taken for selected medications when treating people with diabetic kidney disease (DKD) (continued)

\begin{tabular}{|c|c|}
\hline eGFR level & Action to be taken \\
\hline \multicolumn{2}{|c|}{ DPP-4 inhibitors: vildagliptin, saxagliptin, sitagliptin, linagliptin, alogliptin } \\
\hline For all & $\begin{array}{l}\text { - Older people ( } \geq 65 \text { years): in general, no dose adjustment is recommended based on age. } \\
\text { - Paediatric population: the safety and efficacy of DPP-4 inhibitors in children aged } 0 \text { to }<18 \text { years have not yet been established. No data are } \\
\text { available. } \\
\text { - No dose adjustments are needed for mild to moderate hepatic impairment. Caution needs to be exercised with alogliptin use in those with } \\
\text { severe hepatic impairment. Vildagliptin should not be used in hepatic impairment. Alogliptin and saxagliptin are not recommended in severe } \\
\text { hepatic impairment. Only linagliptin is licensed for use in severe hepatic impairment. } \\
\text { - Acute pancreatitis: DPP-4 inhibitors are associated with risk of developing acute pancreatitis. Caution should be exercised in those with a } \\
\text { history of pancreatitis. } \\
\text { - Heart failure: DPP-4 inhibitors do not increase risk of major CV events or risk of hospitalisation for heart failure except saxagliptin, which is } \\
\text { contraindicated in heart failure. }\end{array}$ \\
\hline$>60 \mathrm{~mL} / \mathrm{min} / 1.73 \mathrm{~m}^{2}$ & - No renal contraindication to initiation or continuation. \\
\hline $\begin{array}{l}45-60 \mathrm{~mL} / \mathrm{min} / \\
1.73 \mathrm{~m}^{2}\end{array}$ & $\begin{array}{l}\text { - eGFR }<50 \mathrm{~mL} / \mathrm{min} / 1.73 \mathrm{~m}^{2} \text {, reduce dose of sitagliptin to } 50 \mathrm{mg} \text { daily, vildagliptin to } 50 \mathrm{mg} \text { once daily, alogliptin to } 12.5 \mathrm{mg} \text { daily and } \\
\text { saxagliptin to } 2.5 \mathrm{mg} \text { daily. No dose reduction needed for linagliptin. }\end{array}$ \\
\hline $\begin{array}{l}30-45 \mathrm{~mL} / \mathrm{min} / \\
1.73 \mathrm{~m}^{2}\end{array}$ & $\begin{array}{l}\text { - Reduce dose of sitagliptin to } 50 \mathrm{mg} \text { daily, vildagliptin to } 50 \mathrm{mg} \text { once daily, alogliptin to } 12.5 \mathrm{mg} \text { daily and saxagliptin to } 2.5 \mathrm{mg} \text { daily. No dose } \\
\text { reduction needed for linagliptin. Vildagliptin has limited data and should be used with caution. }\end{array}$ \\
\hline For all & $\begin{array}{l}\text { - Older people ( } \geq 65 \text { years): in general, no dose adjustment is recommended based on age. } \\
\text { - Paediatric population: the safety and efficacy of dapagliflozin in children aged up to } 18 \text { years have not yet been established. No data are available. } \\
\text { - Active foot disease (either ulceration with sepsis or ischaemia) avoid initiation and withdraw if this occurs. } \\
\text { - Diabetic ketoacidosis (DKA): permanently discontinue if people develop DKA on treatment. }\end{array}$ \\
\hline$>60 \mathrm{~mL} / \mathrm{min} / 1.73 \mathrm{~m}^{2}$ & - No renal contraindication to initiation or continuation. \\
\hline $\begin{array}{l}45-60 \mathrm{~mL} / \mathrm{min} / \\
1.73 \mathrm{~m}^{2}\end{array}$ & $\begin{array}{l}\text { - Canagliflozin } 100 \mathrm{mg} \text { daily may be commenced for glucose lowering and reno-protection. } \\
\text { - Dapagliflozin } 10 \mathrm{mg} \text { daily may be commenced/continued for heart failure and reno-protection. } \\
\text { - Empagliflozin may be commenced/continued for heart failure } \\
\text { - For other drugs, current licence recommends against initiation (but see recommendations). Continuation of medication should be at the lower } \\
\text { dose for canagliflozin and empagliflozin. }\end{array}$ \\
\hline Dialysis & - No current role \\
\hline AKI (or at risk of $\mathrm{AKI}$ ) & $\begin{array}{l}\text { - Review and consider (temporarily) stopping* in people who: } \\
\text { - have acute major changes in renal function (a fall in eGFR of }>10 \mathrm{~mL} / \mathrm{min} / 1.73 \mathrm{~m} 2 \text { over a period of days or weeks)* } \\
\text { - are at risk of AKI such as: } \\
\text { o acute volume depletion and dehydration (eg, gastrointestinal upset, stomas, change in diuretic dose) } \\
\text { o operative procedures with a high risk of hypotension or volume depletion } \\
\text { - in the presence of hypotension or shock (eg severe infection) } \\
\text { * have had previous episodes of AKI. } \\
\text { *Duration of stopping SGLT-2 inhibitor should be based on the likely period of risk. }\end{array}$ \\
\hline
\end{tabular}

or sulfonylureas, a reduction in dose of these drugs should be considered, so as to reduce the risk of hypoglycaemia (Grade 1A).

3. The initiation of SGLT-2 inhibitors in people who have active foot disease (ulceration, infection, sepsis and ischaemia) should be avoided and these agents should be withdrawn in people who develop active infected and/or vascular foot complications while on treatment. SGLT- 2 inhibitors should only be reinstated after foot problems have fully resolved and following discussion with the multidisciplinary foot team (expert opinion, no high grade evidence)

4. SGLT- 2 inhibitors should be withdrawn in all people who develop DKA. However, if a definitive cause for DKA is identified (e.g. low calorie diet, post-operative catabolic state) reinstatement of SGLT-2 inhibitor may be considered depending on careful assessment of the individualised risks and benefits by a 


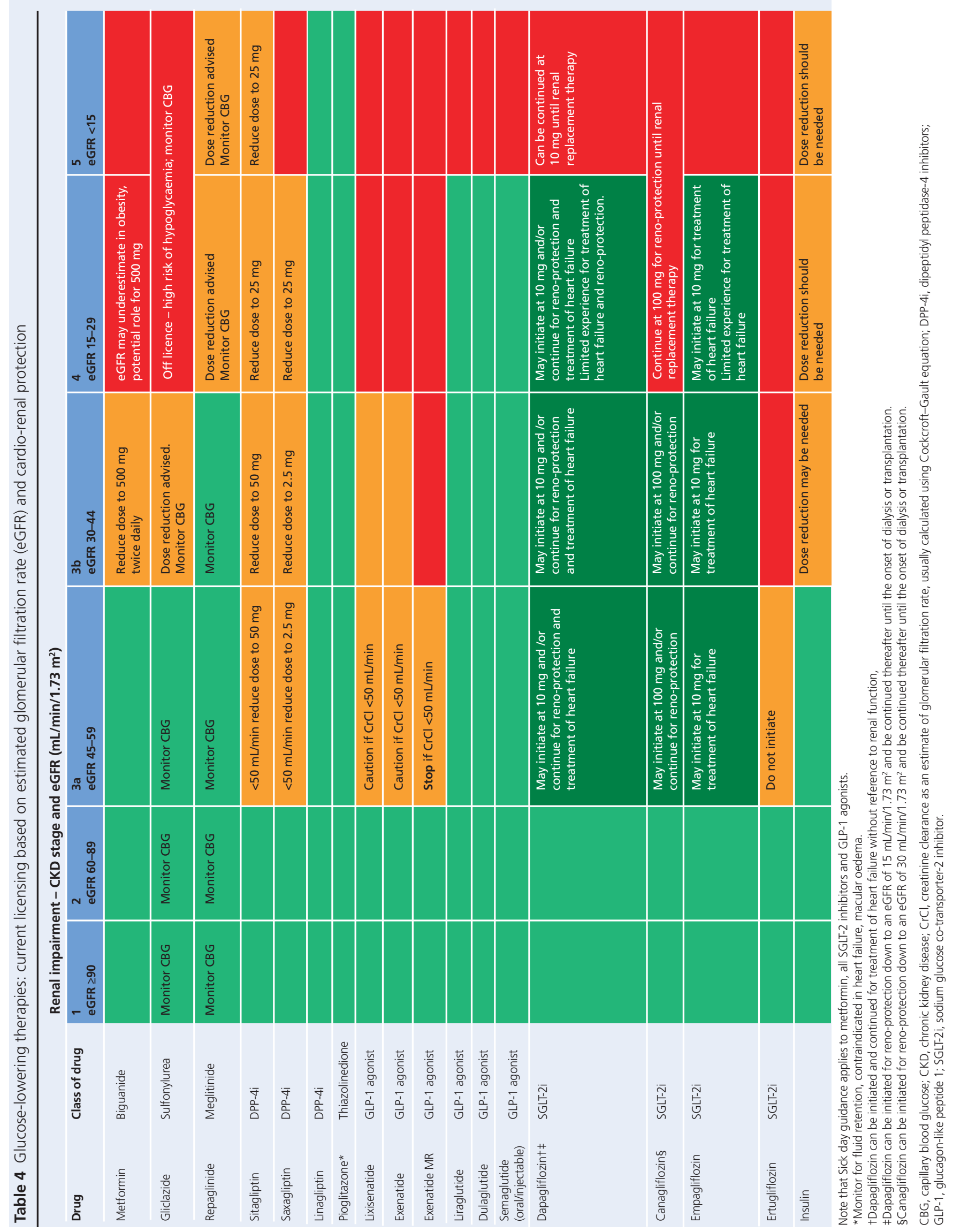


diabetes specialist. (expert opinion, no high grade evidence)

5. We do not recommend routine assessment of renal function (creatinine and/or eGFR) within 6- 8 weeks of SGLT- 2 initiation since there is likely to be a transient and physiological deterioration and this is not a reason to withdraw the drug. (expert opinion, no high grade evidence). Monitoring of renal function after initiation of agents that are associated with dehydration is an im-portant safety issue and should be performed according to clinical need.

6. We recommend that sick day guidance applies, during which SGLT-2 inhibitors should be temporarily withheld. (expert opinion, no high grade evidence)

\section{Glucagon-like peptide-1 receptor agonists}

In 2021, six licensed GLP-1 receptor agonist injectables are available for use in Europe and two involve differing delivery mechanisms for the same molecule (exenatide).

Systematic reviews and meta-analyses suggest a clear beneficial class effect of GLP-1 receptor agonists on the risk of cardiovascular disease (CVD). ${ }^{22,29}$ CVOT have demonstrated CVD benefits with liraglutide, injectable semaglutide, and dulaglutide. There are currently no primary renal endpoint studies with this class of agent published. However the impact of GLP-1 receptor agonist on renal safety and renal outcomes has been as-sessed in several studies as secondary or exploratory outcomes.

There have been isolated case reports of acute kidney injury (AKI) and interstitial nephritis resulting from exenatide and liraglutide use, and these are referred to in their summary of product characteristics. ${ }^{30}$ Acute hypovolaemia from severe gastrointestinal side effects was considered to be a more likely cause of AKI than a direct nephrotoxic effect of these drugs. In practice, it would be reasonable to apply caution for people who have DKD and acute illness via the temporary cessation of GLP-1RA therapy through general sick day guidance.

The current data on potential reno-protection are based on secondary or exploratory CVOTs. However, a placebo-controlled trial of semaglutide with primary renal endpoints is currently ongoing and expected to report in 2024. An exploratory analysis of REWIND assessed the effect of dulaglutide on the renal component of the composite microvascular outcome, defined as the first occurrence of new macroalbuminuria (UACR $>33.9 \mathrm{mg} /$ $\mathrm{mmol}[>300 \mathrm{mg} / \mathrm{g}])$, a sustained decline in eGFR of $30 \%$ or more from baseline, or chronic renal replacement therapy. The renal outcome occurred in $848(17.1 \%)$ participants in the dulaglutide group and in 970 (19.6\%) placebo participants (HR 0.85, 95\% Cl 0.77- 0.93; $p=0.0004) .{ }^{31}$ The major driver was new onset macroalbuminuria (HR 0.77, 95\% Cl 0.68- 0.87; $p<0.0001$ ), with HRs of $0.89(0.78-1.01 ; p=0.066)$ for sustained decline in eGFR of $30 \%$ or more and $0.75(0.39-1.44 ; p=0.39)$ for chronic renal replacement therapy. Dulaglutide is now licensed in the UK for glucose lowering at doses of 3.0 and $4.5 \mathrm{mg}$ once weekly. The safety profiles of these higher doses are consistent with those reported for dulaglutide with no additional renal data reported at the time of this publication and the recommended renal threshold is as for the 0.75 and $1.5 \mathrm{mg}$ once weekly dosing. No dose adjustment of dulaglutide is required for people with mild, moderate or severe renal impairment and so it may be used in people with an eGFR of $>15 \mathrm{~mL} / \mathrm{min} / 1.73 \mathrm{~m}^{2}$. Experience of the use of dulaglutide in people with eGFR $<15$ is limited and so it is not recommended for use in ESKD.

Secondary analyses of the SUSTAIN 6 trial on renal microvascular outcomes demonstrated a significant reduction of the composite renal endpoint (HR 0.64; $\mathrm{Cl} 0.46-0.88 ; \mathrm{p}=0.005$ ) with semaglutide once weekly. ${ }^{32}$ Once again, this benefit was driven by a fall in new cases of persistent macroalbuminuria ( $2.5 \%$ versus $4.9 \%$ of cases) whereas the number of people who had a doubling of serum creatinine and/or needed continuous renal replacement therapy was small and similar between groups.

According to the summary of product characteristics no dose adjustment of semaglutide is required for people with mild, moderate or severe renal impairment and so it may be used in people with an eGFR of $>15 \mathrm{~mL} / \mathrm{min} / 1.73 \mathrm{~m}^{2}$. Experience of the use of semaglutide in people with eGFR $<15 \mathrm{~mL} / \mathrm{min}$ is limited and so it is not recommended for use in ESKD. No GLP-1RAs are currently licensed for use in people with CKD stage 5 in the UK, nor for those on renal dialysis.

An oral form of semaglutide was licensed in the UK in 2020, which is administered once daily. The view of the regulatory bodies appears to be that the safety of the semaglutide molecule is the same, irrespective of the mode of administration. Hence the renal limitations for oral semaglutide are the same as those for the once weekly injectable formulation.

\section{Recommendations}

1. To date, there has been no reported reduction in hard clinical endpoints, such as a doubling of serum creatinine or the need for continuous renal replacement therapy with GLP-1 RA. There is evidence that treatment with some GLP-1RAs reduce the progression of renal disease in people with type 2 diabetes, but this mainly relates to the new onset of persistent macroalbuminuria (Grade 2B).

2. Hence, the main aim of GLP-1 RA therapy in people with DKD should be the improvement of glycaemic control with a low risk of both hypoglycaemia and weight gain (Grade 1A).

3. There is evidence of protection from cardiovascular disease with some GLP-1RAs in people who have type 2 diabetes and a high risk of cardiovascular disease (Grade $1 \mathrm{~A}$ ).

4. In one sub-group analysis, this protection was more pronounced in people with stage 3 CKD; GLP-1RAs are, therefore, preferred over alternative glucose-lowering therapies (eg sulfonylureas and insulins) in this scenario (Grade 2B).

5. People with DKD who are treated with GLP- 1RAs need to only perform regular self-monitoring of blood glucose when they are also being treated with drugs that can cause hypoglycaemia (sulfonylureas and insulins) (Grade 1A).

6. There is no role for the combination of GLP-1 analogues and DPP-4 inhibitors (Grade 1C).

\section{GLP-1RA and insulin co-formulations}




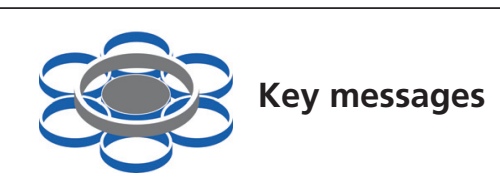

- People with diabetic kidney disease (DKD) have an increased risk of CVD morbidity and mortality

- Individualised $\mathrm{HbA}_{1 \mathrm{c}}$ targets should be applied in the management of people with DKD

- SGLT-2 inhibitors significantly reduce progression of DKD and prevent ESKD in people with T2DM

- We recommend the consideration of SGLT-2 inhibitors in all individuals with type 2 diabetes and DKD with an eGFR $\geq 30 \mathrm{~mL} / \mathrm{min} / 1.73 \mathrm{~m}^{2}$

Two co-formulations of GLP-1RAs and basal insulin are now available in the UK; Xultophy ${ }^{\mathrm{TM}}$ is made up of liraglutide and insulin degludec while Suliqua ${ }^{\mathrm{TM}}$ is a combination of lixisenatide and insulin glargine U100. The renal limitations for these fixed ratio formulations are those of their respective GLP-1RAs. There are no current specific trials of these combinations in DKD.

\section{Conclusion}

People with DKD have increased risk of morbidity and mortality. Hyperglycaemia is a modifiable risk factor for cardiovascular complications and progression of DKD. Individualised $\mathrm{HbA}_{1 \mathrm{c}}$ targets should be applied in the management of people with DKD, using the levels suggested in this guidance. Delaying ESKD and reducing CVD risk are essential to improve outcomes in this highrisk population. There is now conclusive evidence and consensus that SGLT-2 inhibitors significantly reduce progression of DKD and onset of ESKD in people with Type 2 diabetes and albuminuria. Results of ongoing studies will determine the renal benefits of this class in people with DKD and normo-albuminuria and in people with type 1 diabetes.

Conflict of interest SB has received honoraria, teaching and research sponsorship/grants from Abbott, AstraZeneca, Boehringer Ingelheim, Eli Lilly, Merck Sharp \& Dohme, Novo Nordisk, Roche and Sanofi Aventis. He has also received funding for the development of educational programmes from: Elsevier, OmniaMed and Medscape. He is a partner in Glycosmedia, which carries sponsorship declared on its website. DB was previously funded for research by the British Heart Foundation (BHF). He is funded by ESR AstraZeneca for clinical trials. He has received speaker fees from Vifor Pharma and AstraZeneca. TC has no conflicts of interest. DP has received honoraria for advisory work and/or lecture fees from AstraZeneca, Boehinger Ingelheim Eli Lilly, MSD and Napp Pharmaceuticals, Novo Nordisk and Sanofi. ID has previously received research grants from Medtronic and Daiichi Sankyo. He has been a member of advisory committees and received educational grants from AstraZeneca, Amgen, Sanofi, MSD, Pfizer, GSK, Mitsubishi Pharma, Otsuka, Vifor Pharmaceuticals, Fresenius and Roche. PD has received honoraria for educational meetings from AstraZeneca, Janssen, Boehringer Ingelheim, Novo, Sanofi, Novartis, Abbott, MSD, Takeda, Roche, Lilly, Ascensia, BD, Internis, GSK, Menarini, Bayer and Besins. PM has received honoraria from Pfizer, AstraZeneca, Novartis, Bristol Myers Squibb, Napp, Vifor and Pharmacosmos and research support from Boehringer Ingelheim outside this work. DF has received honoraria for delivering educational meetings and/or attend- ing advisory boards from AstraZeneca, Sanofi, Vifor Pharmaceuticals and Baxter. He provides consultancy for adjudication of endpoint in RCTs to ACl. AF has received research grants, and he prepares educational materials and attends drug advisory boards for Boehringer Ingelheim/Lilly Alliance, AstraZeneca, Novo Nordisk, Merck and Johnson \& Johnson. AP has received honoraria for attending and delivering non-promotional educational meetings and advisory boards from Lilly, NovoNordisk and Boehringer Ingelheim. PW has received honoraria for delivering educational meetings and/or attending advisory boards for AstraZeneca, Eli Lilly, Novo Nordisk, Sanofi, MSD, Janssen and Vifor Pharmaceuticals. JK has received honoraria for delivering educational meetings and/or attending advisory boards Boehringer Ingelheim, AstraZeneca, Sanofi, Janssen, Novo Nordisk and research grants from AstraZeneca, Sanofi. RMM has no conflicts of interest to declare. AS has received honoraria for delivering educational meetings and/or attending advisory boards for Boehringer Ingelheim/Lilly Alliance, Napp Pharmaceuticals, Novo Nordisk, Astellas, Sandoz and Atara Biotherapeutics. He currently has grant funding from Chiesi UK.

\section{Funding None.}

\section{References}

1. Buse JB, Wexler DJ, Tsapas A, et al. 2019 Update to: Management of hyperglycemia in type 2 diabetes, 2018. A consensus report by the American Diabetes Association (ADA) and the European Association for the Study of Diabetes (EASD). Diabetes Care 2020;43(2):487-93. https://doi.org/10.2337/dci19-0066

2. Cosentino F, Grant PJ, Aboyans V, et al. 2019 ESC guidelines on diabetes, pre-diabetes, and cardiovascular diseases developed in collaboration with the EASD. Eur Heart J 2020;41(2):255-323. https://doi.org/ 10.1093/eurheartj/ehz486

3. de Boer IH, DCCT/EDIC Group, Kidney disease and related findings in the Diabetes Control and Complications Trial/Epidemiology of Diabetes Interventions and Complications Study. Diabetes Care 2014;37(1):2430. https://doi.org/10.2337/dc13-2113

4. Lind M, Svensson A-M, Kosiborod M, et al. Glycemic control and excess mortality in type 1 diabetes. N Engl J Med 2014;371(21):1972-82. https://doi.org/10.1056/NEJMoa1408214

5. Coca SG, Ismail-Beigi F, Haq N, Krumholz HM, Parikh CR. Role of Intensive glucose control in development of renal end points in type 2 diabetes mellitus: systematic review and meta-analysis. Arch Intern Med 2012;172(10):761-9. https://doi.org/10.1001/archinternmed.2011.2230

6. Rodríguez-Gutiérrez R, Montori VM. Glycemic control for patients with type 2 diabetes mellitus: our evolving faith in the face of evidence. Circ Cardiovasc Qual Outcomes 2016;9(5):504-12. https://doi.org/10.1161/ CIRCOUTCOMES.116.002901

7. Zoungas $\mathrm{S}$, Arima H, Gerstein HC, et al. Effects of intensive glucose control on microvascular outcomes in patients with type 2 diabetes: a metaanalysis of individual participant data from randomised controlled trials. Lancet Diabetes Endocrinol 2017;5(6):431-7. https://doi.org/10.1016/ S2213-8587(17)30104-3

8. Wang Y, Katzmarzyk PT, Horswell R, Zhao W, Johnson J, Hu G. Comparison of the heart failure risk stratification performance of the CKD$\mathrm{EPI}$ equation and the MDRD equation for estimated glomerular filtration rate in patients with type 2 diabetes. Diabet Med 2016;33(5):609-20. https://doi.org/10.1111/dme.12859

9. Nair S, Mishra V, Hayden K, et al. The four-variable modification of diet in renal disease formula underestimates glomerular filtration rate in obese type 2 diabetic individuals with chronic kidney disease. Diabetologia 2011;54(6):1304-7. https://doi.org/10.1007/s00125-011-2085-9

10. Diao JA, Inker LA, Levey AS, Tighiouart H, Powe NR, Manrai AK. In search of a better equation - performance and equity in estimates of kidney function. N Engl J Med 2021;384(5):396-9. https://doi.org/ 10.1056/NEJMp2028243

11. Pilz S, Rutters F, Nijpels $G$, et al. Insulin sensitivity and albuminuria: the RISC study. Diabetes Care 2014;37(6):1597-603. https://doi.org/ $10.2337 / \mathrm{dc} 13-2573$

12. Biesenbach G, Rami A, Schmekal B, Eichbauer-Sturm G. Decreased insulin requirement in relation to GFR in nephropathic type 1 and insulin- 
treated type 2 diabetic patients. Diabet Med 2003;20(8):642-5. https://doi.org/10.1046/j.1464-5491.2003.01025.x

13. Javier Escalada F, Halimi S, Senior PA, et al. Glycaemic control and hypoglycaemia benefits with insulin glargine $300 \mathrm{U} / \mathrm{mL}$ extend to people with type 2 diabetes and mild-to-moderate renal impairment. Diabetes Obes Metab 2018;20(12):2860-8. https://doi.org/10.1111/dom.13470

14. Haluzík M, Cheng A, Muller-Wieland D, et al. Differential glycaemic control with basal insulin glargine $300 \mathrm{U} / \mathrm{mL}$ versus degludec $100 \mathrm{U} / \mathrm{mL}$ according to kidney function in type 2 diabetes: a subanalysis from the BRIGHT trial. Diabetes Obes Metab 2020;22(8):1369-77. https://doi.org/10.1111/dom.14043

15. Snyder RW, Berns JS. Reviews: use of insulin and oral hypoglycemic medications in patients with diabetes mellitus and advanced kidney disease: diabetic medication in kidney disease. Semin Dialysis 2004; 17(5):36570. https://doi.org/10.1111/j.0894-0959.2004.17346.x

16. Frankel A, Kazempour-Ardebili S, Bedi R, et al. Management of adults with diabetes on the haemodialysis unit: summary of new guidance from the Joint British Diabetes Societies (JBDS) and the Renal Association. Br J Diabetes 2016:16(2):69. https://doi.org/10.15277/bjd.2016.073

17. Home P, Mant J, Diaz J, Turner C, Guideline Development Group. Management of type 2 diabetes: summary of updated NICE guidance. BMJ 2008;336(7656):1306-8. https://doi.org/10.1136/bmj.39560.442095.AD

18. Crowley MJ, Diamantidis C, McDuffie JR, et al. Clinical outcomes of metformin use in populations with chronic kidney disease, congestive heart failure, or chronic liver disease: a systematic review. Ann Intern Med 2017;166(3):191-200. https://doi.org/10.7326/M16-1901

19. Lazarus B, Wu A, Shin J-I, et al. Association of metformin use with risk of lactic acidosis across the range of kidney function: a community-based cohort study. JAMA Intern Med 2018;178(7):903-10. https://doi.org/10.1001/jamainternmed.2018.0292

20. Inzucchi SE, Lipska KJ, Mayo H, Bailey CJ, McGuire DK. Metformin in patients with type 2 diabetes and kidney disease: a systematic review. JAMA 2014;312(24):2668-75. https://doi.org/10.1001/jama.2014.15298

21. Monami M, Dicembrini I, Martelli D, Mannucci E. Safety of dipeptidyl peptidase-4 inhibitors: a meta-analysis of randomized clinical trials. Curr Med Res Opin 2011;27(Suppl 3):57-64. https://doi.org/10.1185/ 03007995.2011 .602964

22. Palmer SC, Tendal B, Mustafa RA, et al. Sodium-glucose cotransporter protein-2 (SGLT-2) inhibitors and glucagon-like peptide-1 (GLP-1) receptor agonists for type 2 diabetes: systematic review and network meta- analysis of randomised controlled trials. BMJ 2021;372:m4573. https://doi.org/10.1136/bmj.m4573

23. Zelniker TA, Wiviott HD, Raz I, et al. SGLT2 inhibitors for primary and secondary prevention of cardiovascular and renal outcomes in type 2 diabetes: a systematic review and meta-analysis of cardiovascular outcome trials. Lancet 2019;393(10166):31-9. https://doi.org/10.1016/S01406736(18)32590-X

24. Neuen BL, Young T, Heerspink HJL, et al. SGLT2 inhibitors for the prevention of kidney failure in patients with type 2 diabetes: a systematic review and meta-analysis. Lancet Diabetes Endocrinol 2019;7(11):84554. https://doi.org/10.1016/\$2213-8587(19)30256-6

25. Wanner C, Inzucchi SE, Lachin JM, et al. Empagliflozin and progression of kidney disease in type 2 diabetes. N Engl J Med 2016;375(4):323-34 https://doi.org/10.1056/NEJMoa1515920

26. Cannon CP, Pratley R, Dagogo-J ack S, et al. Cardiovascular outcomes with ertugliflozin in Type 2 diabetes. N Engl J Med 2020;383(15):14251435.

27. Perkovic $V$, Jardine MJ, Neal B, et al. Canagliflozin and renal outcomes in type 2 diabetes and nephropathy. N Engl J Med 2019;380(24):2295306. https://doi.org/10.1056/NEJMoa1811744

28. Heerspink HJL, Stefansson BV, Corea-Rotter R, et al. Dapagliflozin in patients with chronic kidney disease. N Engl J Med 2020;383(15):143646. https://doi.org/10.1056/NEJMoa2024816

29. Sattar N, Lee MMY, Kristensen SL, et al. Cardiovascular, mortality, and kidney outcomes with GLP-1 receptor agonists in patients with type 2 diabetes: a systematic review and meta-analysis of randomised trials. Lancet Diabetes Endocrino/ 2021;9(10):653-62. https://doi.org/10.1016/ S22138587(21)00203-5

30. Gariani K, de Seigneux S, Moll S. Acute interstitial nephritis after treatment with liraglutide. Am J Kidney Dis 2014;63(2):347. https://doi.org/ 10.1053/j.ajkd.2013.10.057

31. Gerstein HC, Colhoun HM, Dagenais GR, et al. Dulaglutide and renal outcomes in type 2 diabetes: an exploratory analysis of the REWIND randomised, placebo-controlled trial. Lancet 2019;394(10193):131-8. https://doi.org/10.1016/S0140-6736(19)31150-X

32. Marso SP, Bain SC, Consoli A, et al. Semaglutide and cardiovascular outcomes in patients with type 2 diabetes. N Engl J Med 2016; 375(19):1834-44. https://doi.org/10.1056/NEJMoa1607141 
Appendix 1. Evidence grades for the recommendations

The following evidence grading has been used to determine the strength of the recommendations:

$1 \mathrm{~A}$ Strong recommendation: high-quality evidence

1B Strong recommendation: moderate-quality evidence

1C Strong recommendation: low-quality evidence

1D Strong recommendation: very low-quality evidence

2A Weak recommendation: high-quality evidence

2B Weak recommendation: moderate-quality evidence

2C Weak recommendation: low-quality evidence

2D Weak recommendation: very low-quality evidence 